\title{
Is downstream cardiac testing required in patients with reduced functional capacity and otherwise negative exercise stress test? A single center observational study
}

\author{
Mark Whitman ${ }^{1,2}$, Surendran Sabapathy ${ }^{2,3}$, Carly Jenkins ${ }^{1}$, Lewis Adams ${ }^{2,3}$ \\ ${ }^{1}$ Cardiac Investigations Unit, Logan Hospital, Meadowbrook, Australia \\ ${ }^{2}$ Menzies Health Institute Queensland, Australia \\ ${ }^{3}$ School of Allied Health Sciences, Griffith University, Gold Coast, Australia
}

\begin{abstract}
Background: Exercise stress testing (EST) in patients with poor functional capacity measured by time on treadmill is typically deemed inconclusive and usually leads to further downstream testing. The aim of this study was firstly to evaluate the maximum rate pressure product (MRPP) during initial EST to assessthe need for follow-up testing; and secondly to investigate if MRPP is better than age predicted maximum heart rate (APMHR) for diagnostic outcome based on follow up cardiovascular (CV) events in patients with inconclusive EST due to poor functional capacity.

Methods: From a total of 2761 tests performed, 236 tests were considered inconclusive due to poor functional capacity which were available for analysis. From receiver operating characteristic (ROC) analysis, a cut-off value for MRPP of 25000 was chosen using CV events as the outcome measure (sensitivity 97\%, specificity 45\%). Cases were then categorised into those with an MRPP > 25000 and $<25000$.
\end{abstract}

Results: Regardless of treadmill time, any patient attaining an MRPP $>25000$ had no abnormal downstream testing or CV events at 2 years follow-up. On ROC analysis MRPP outperformed APMHR for sensitivity and specificity (area under curve $0.76 \mathrm{vs.} 0.59$, respectively).

Conclusions: The results suggest that regardless of functional capacity, individuals whose EST is terminated at maximal fatigue, with no electrocardiogram evidence or symptoms of myocardial ischemia and yields an MRPP > 25000, do not require further downstream testing. Furthermore, this group of patients, while not immune to future CV events, have significantly better outcomes than those not attaining a MRPP > 25000. (Cardiol J 2019; 26, 6: 753-760)

Key words: rate pressure product, exercise stress testing, myocardial ischemia, double product, myocardial index

\section{Introduction}

Exercise stress testing (EST) in patients with poor functional capacity measured solely by time on treadmill is typically deemed inconclusive and usually leads to further investigation such as exercise stress echo or dobutamine stress echo, myocardial perfusion imaging, computed tomography coronary angiography or conventional coronary angiography (CA). There is inherent risk involved to the patient with some of these tests along with the expense of performing such procedures. A more direct as-

Address for correspondence: Mark Whitman, BExSc, Cardiac Investigations Unit, Clinical Measurements Department, Logan Hospital, PO Box 6031, Yatala, Queensland. 4207, Australia, tel: 6173299 8876, fax: 6173299 8117, e-mail: mark.whitman@health.qld.gov.au

Received: 23.01.2018_ Accepted: 7.07.2018 
sessment of cardiac workload achieved during EST would enable better discrimination between tests where cardiac stress was inadequate and those with adequate cardiac stress but poor functional capacity. A well validated index of cardiac stress, rate pressure product (RPP), although easily available, is not routinely used in clinical practice to evaluate this important aspect of the test. Normal values for RPP have been proposed for clinical and nonclinical populations at rest and at maximal exercise [1-3]. During EST, RPP has been extensively investigated as a prognostic variable [4-7]. In a retrospective cohort study of 1759 men, rate pressure product reserve (RPPR) (the difference between $\mathrm{RPP}$ at rest and maximal exercise) was the strongest predictor of 7-year cardiovascular (CV) status, even after adjustment for age, beta-blocker use and Duke Treadmill Score [4]. In the same study, RPPR was shown to have greater prognostic power than maximum metabolic equivalents (METS), itself a key independent predictor of all-cause and CV mortality [8, 9]. In addition, RPP has been shown to increase the predictive value of EST when screening for coronary artery disease (CAD) $[6,7]$. However, no previous study has used RPP as a marker of significant cardiac stress in patients with reduced functional capacity and otherwise negative EST results. The aim of this study was firstly to retrospectively evaluate the MRPP during EST to determine the necessity of downstream testing in patients with reduced functional capacity $(>15 \%$ below age and gender predicted functional capacity) with an otherwise negative test for myocardial ischemia; and secondly assess if MRPP outperforms age predicted maximum heart rate (APMHR) for diagnostic outcome based on CV events occuring during the follow-up period.

\section{Methods}

The study sample was drawn from the Logan Hospital, a medium-sized public hospital in southeast Queensland, Australia, and was approved by the Metro South Health Service District Human Research Ethics Committee, and conforms to the declaration of Helsinki. Retrospective data were retrieved from all ESTs performed within a 5-year window (July 2007 to June 2012). Presentation with chest pain suspected to be caused by CAD was the main reason for performing EST. All ESTs were administered by the same core group of staff on a computer-controlled treadmill system (Marquette Case; Milwaukee, WI) using the standard Bruce protocol [10]. Manual blood pressure measure- ments were taken by an experienced operator at least once every stage, at peak exercise, and a minimum of twice during recovery. RPP was calculated by multiplying heart rate (HR) by systolic blood pressure (SBP) at each stage and maximal rate pressure product (MRPP) was identified. Maximum HR and maximum SBP achieved during the test were also recorded. Patients received a thorough evaluation to assess suitability and to rule out clinical evidence of heart failure prior to testing.

The total number of tests performed during the collection period was 2761 . Any stress test deemed negative (2019), positive or equivocal (401) (based on electrocardiography changes or symptoms of myocardial ischemia), or indeterminate (69) (due to non-cardiorespiratory limitation) was excluded from the study, leaving a total of 272 inconclusive tests. From the 272 tests a further 36 with known $\mathrm{CAD}$ were removed from analysis as different clinical management strategies would be indicated compared to those without known CAD (Fig. 1). The remaining 236 tests were selected for analysis based on a functional capacity $<85 \%$ of age and gender predicted totals performed during the initial EST. This chosen cut-off value for functional capacity was selected in order to standardise "poor functional capacity" among our cohort and has been previously demonstrated to infer a 2-fold absolute risk in CV mortality [9, 11, 12]. The decision to perform further testing in this group was determined by the treating physician based on a patient's intermediate or moderate pretest risk for CAD (minimum of $10 \%$ risk in 5 years as per Australian Vascular Disease Prevention Alliance) [13] and poor functional capacity. Tests were typically performed within 4 weeks from the initial test. Mean follow-up was $5 \pm 2.4$ years (range $2-9$ years) by referencing medical records or through contact with the patients' general practitioner. Complete follow-up was possible in all patients up to 2 years and potential cost savings of further downstream testing generated during this period was established.

A receiver operating characteristic (ROC) curve (Fig. 2) was created to establish the MRPP cut-point using CV events at mean follow-up (5 years) as the outcome. The cut-point chosen was the longest vertical deviation from the diagonal line and corresponded to a MRPP of 25000 (sensitivity $97 \%$, specificity $45 \%$, area under curve [AUC] 0.76). Two groups were then established for analysis: inconclusive EST with MRPP $>25000$ (MRPP > 25), and inconclusive EST with MRPP $<25000$ (MRPP < 25). ROC analysis was also 


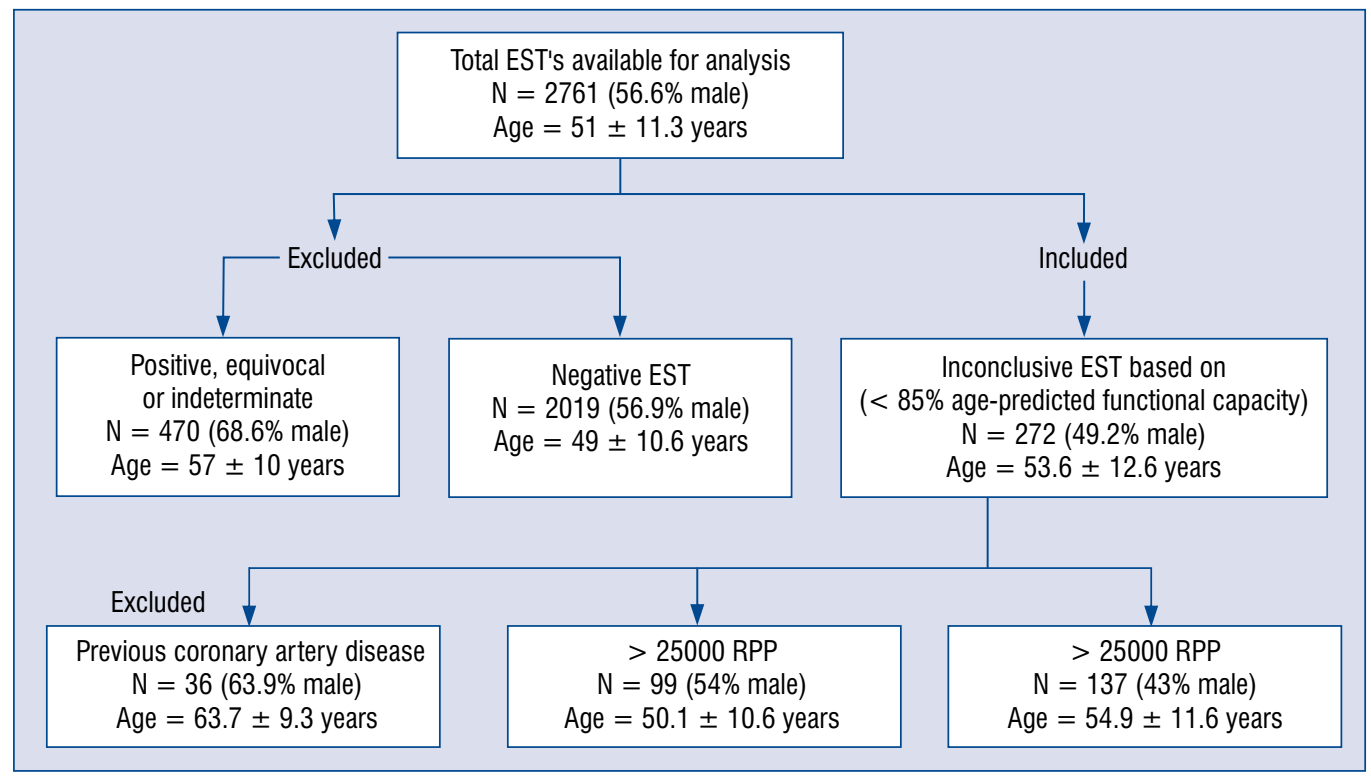

Figure 1. Study sampling frame; EST — exercise stress testing; RPP — rate pressure product.

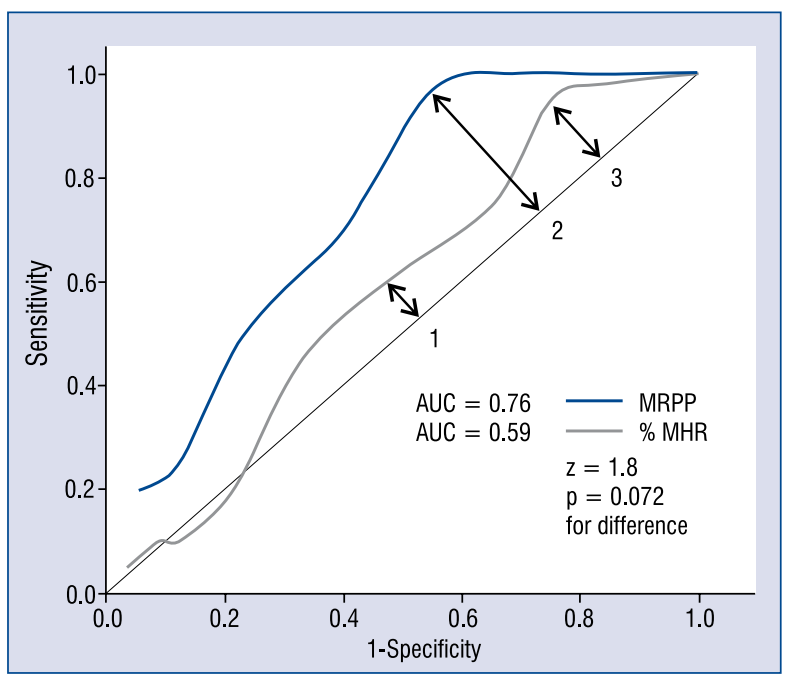

Figure 2. The receiver operating characteristic curve for maximum rate pressure product (MRPP) and agepredicted maximal heart rate (APMHR); 1 - the point corresponding to $\geq 85 \%$ APMHR; 2 - the longest vertical duration for MRPP; 3 - the longest vertical duration for APMHR; AUC — area under curve.

performed for APMHR (AUC 0.59) based on the equation 220 minus age, in order to compare the sensitivity and specificity of this commonly used measure of sufficient cardiac stress against MRPP.

\section{Statistical analysis}

Quantitative data were summarized as mean \pm standard deviation and $t$ tests for independent samples were used to compare variables between the two groups. Kaplan-Meier curves were created to evaluate all-cause mortality, CV mortality (myocardial infarction, heart failure or undifferentiated sudden cardiac death) and CV events (CV mortality, non fatal myocardial infarction, percutaneous coronary intervention [PCI]/balloon angioplasty or coronary artery bypass grafting), and the log rank test was used to assess statistical significance. Cox proportional hazard models were used to establish variables significant for all-cause mortality, CV mortality and CV events. Catagorical data were compared using the Fisher exact test. Data analysis was performed using XLSTAT 2017.6 (Addinsoft, New York) with a 2 -tailed $\mathrm{p}$ value $<0.05$ considered statistically significant.

\section{Results}

Table 1 presents the physical characteristics of patients together with their EST measures. There was no significant difference in sex distribution between the two groups ( $\mathrm{p}=0.107)$, however the MRPP $>25$ group were younger $(\mathrm{p}<0.001)$. Resting measures of HR and SBP were significantly lower in the MRPP $<25$ group $(\mathrm{p}<0.001$ and $\mathrm{p}=0.002$, respectively). There were significant differences in maximum HR, maximum SBP, RPPR, APMHR $(\mathrm{p}<0.001)$ treadmill time $(\mathrm{p}=0.009)$ and $\operatorname{METS}(\mathrm{p}=0.003)$ between the groups. There were more patients with obesity in the MRPP $>25$ group compared to the MRPP $<25$ group ( $=0.04$ ). 
Table 1. Physical characteristics, exercise stress test measures, cardiovascular disease risk factors and medications at time of stress test by rate pressure product (RPP) group.

\begin{tabular}{|c|c|c|c|}
\hline & Maximum RPP > 25000 & Maximum RPP $<25000$ & $\mathbf{p}$ \\
\hline Total & 99 & 137 & \\
\hline Age [years] & $50.1 \pm 10.6^{*}$ & $54.9 \pm 11.6$ & $<0.001$ \\
\hline Male & $53(54 \%)$ & $59(43 \%)$ & 0.1 \\
\hline CVD risk factors & $2.3 \pm 1.4$ & $2.0 \pm 1.3$ & 0.1 \\
\hline Resting HR [bpm] & $77 \pm 15^{*}$ & $71 \pm 13$ & $<0.001$ \\
\hline Resting SBP [mmHg] & $130 \pm 15^{*}$ & $123 \pm 17$ & 0.002 \\
\hline Treadmill time [min:s] & $5: 32 \pm 2: 28^{*}$ & $4: 42 \pm 2: 28$ & 0.009 \\
\hline Metabolic equivalents & $7.2 \pm 2.4^{*}$ & $6.5 \pm 2.4$ & 0.003 \\
\hline Maximum SBP [mmHg] & $188 \pm 21^{*}$ & $155 \pm 19$ & $<0.001$ \\
\hline Maximum HR [bpm] & $162 \pm 19^{*}$ & $130 \pm 20$ & $<0.001$ \\
\hline RPPR & $20177 \pm 4243^{*}$ & $11351 \pm 3251$ & $<0.001$ \\
\hline APMHR [\%] & $95.3 \pm 9.4^{*}$ & $78.7 \pm 11.4$ & $<0.001$ \\
\hline APMHR $<85 \%$ & $12(12.1 \%)^{*}$ & $96(70.1 \%)$ & $<0.001$ \\
\hline No risk factors & $8(8.0 \%)$ & $17(12.4 \%)$ & 0.4 \\
\hline Family history & $33(33.3 \%)$ & $26(19.0 \%)$ & 0.06 \\
\hline Diabetes mellitus & $30(30.3 \%)$ & $24(17.5 \%)$ & 0.09 \\
\hline Smoking & $32(32.3 \%)$ & $59(43.1 \%)$ & 0.3 \\
\hline Hypertension & $41(41.4 \%)$ & $63(46.0 \%)$ & 0.7 \\
\hline Dyslipidemia & $39(39.4 \%)$ & $58(42.3 \%)$ & 0.8 \\
\hline Obesity & $45(45.5 \%)^{*}$ & $36(26.3 \%)$ & 0.04 \\
\hline No medications & $51(51.5 \%)$ & $60(43.8 \%)$ & 0.5 \\
\hline Beta-blockers & $12(12.1 \%)$ & $25(18.2 \%)$ & 0.3 \\
\hline $\mathrm{Ca} 2+$ blockers & $7(7.0 \%)$ & $18(13.1 \%)$ & 0.2 \\
\hline ACE inhibitors & $14(14.1 \%)$ & $26(19.0 \%)$ & 0.5 \\
\hline ARB's & $13(13.1 \%)$ & $13(9.5 \%)$ & 0.5 \\
\hline Nitrates & $1(1.0 \%)$ & $7(5.1 \%)$ & 0.1 \\
\hline Statins & $26(26.3 \%)$ & $50(36.5 \%)$ & 0.3 \\
\hline
\end{tabular}

${ }^{*}$ Significant $p<0.05$. Values show number of cases $(n)$, mean \pm standard deviation or percentage (\%) of the group. ACE - angiotensin converting enzyme; APMHR - age predicted maximum heart rate; APMHR < 85\% — age predicted maximum heart rate less than $85 \%$; ARB — angiotensin receptor blocker; CVD - cardiovascular disease; HR - heart rate; RPPR — rate pressure product reserve; SBP — systolic blood pressure

There were no significant differences between the groups with respect to any other measures (Table 1). Cox proportional hazard analysis failed to demonstrate any significant variable with respect to all-cause mortality or CV mortality. Age was the only significant predictor for $\mathrm{CV}$ events $\left(\chi^{2} 5.4, \mathrm{p}=\right.$ $=0.02$, hazard ratio $1.07,95 \%$ CI 1.011-1.132). For APMHR, the longest vertical deviation from the diagonal on ROC analysis (Fig. 2) corresponded to $95 \%$ (sensitivity $95 \%$, specificity $25 \%$ ). At $85 \%$ APMHR the sensitivity and specificity was $60 \%$ and 53\%, respectively. While a statistical trend was noted between assessments of ROC curves for MRPP and APMHR, overall this failed to reach significance $(z=1.8, \mathrm{p}=0.072$; Fig. 2$)$.
All-cause mortality between the two groups is shown in Figure 3, with a survival trend towards the MRPP $>25$ group $(\mathrm{p}=0.08)$. Both CV mortality and events are also displayed in Figure 2. During the 9 year follow-up, 6 patients in the

MRPP $<25$ group passed away due to CV cause ( 5 heart failure, 1 ventricular fibrillation arrest), with no fatalities in the MRPP $>25$ group; reaching statistical significance at 6 years $(\mathrm{p}<0.05)$. The difference in incidence of $\mathrm{CV}$ events (MRPP $>25=3$ PCI, MRPP $<25=3$ balloon angioplasty, 5 PCI, 4 NSTEMI, 2 STEMI) between the groups reached statistical significance $(\mathrm{p}<0.05)$ from 2 year follow up, with the MRPP $>25$ group displaying superior outcomes. 

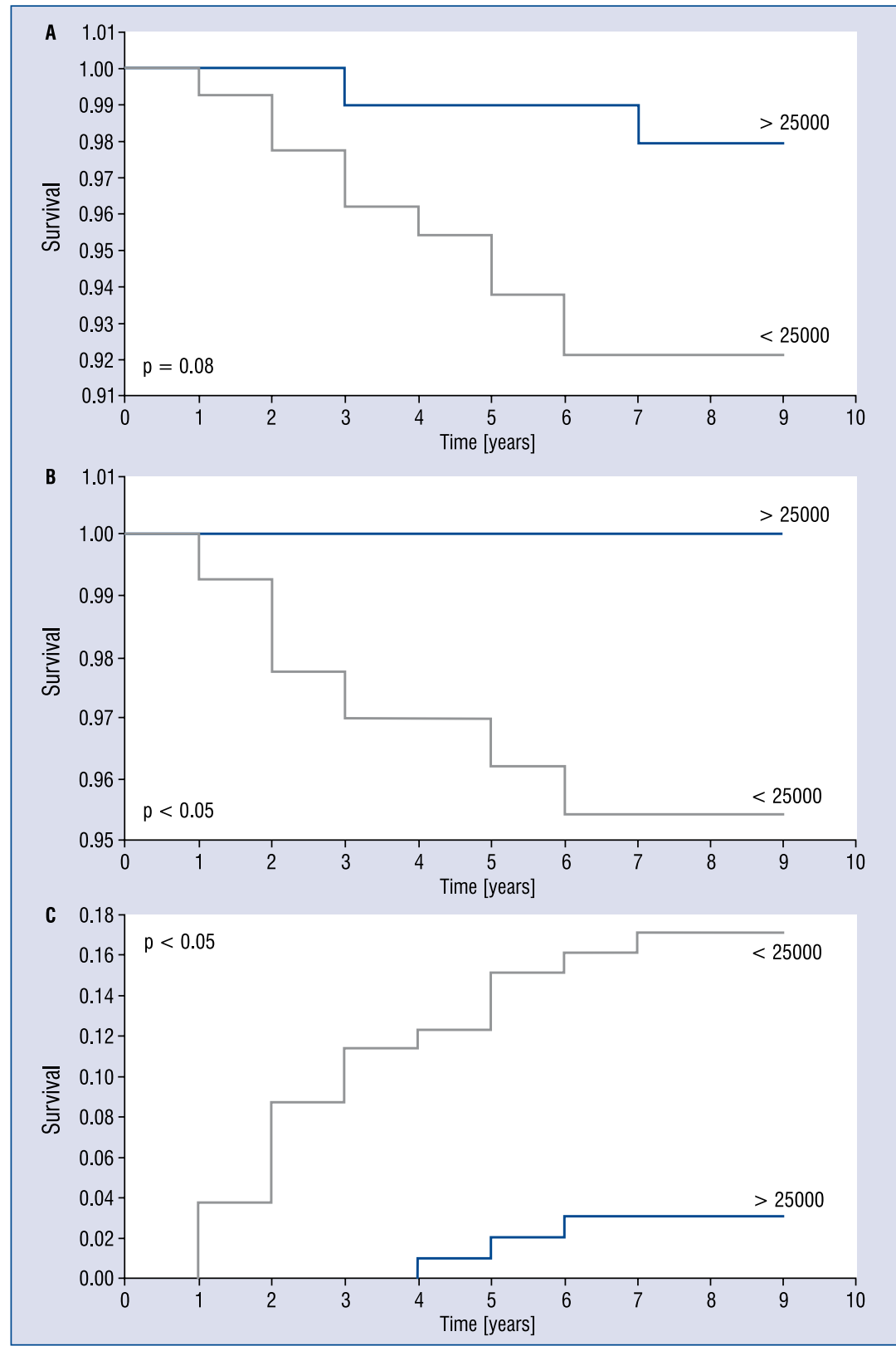

Figure 3. A. All-cause mortality for rate pressure product groups; B. Cardiovascular mortality for rate pressure product groups; C. Cumulative cardiovascular events for rate pressure product groups.

Table 2 displays the number, type and result of downstream testing in both groups performed during the initial 2 year follow-up period. A total of 81 downstream tests were generated in the MRPP $>25$ group and 143 in the MRPP $<25$ group. These totals include subsequent testing by CA which was performed on all occasions when the initial downstream test was positive. None of the 17 patients receiving a CA in the MRPP $>25$ group had a positive result, conversely there were 11 positive tests discovered from 35 CAs performed in the MRPP $<25$ group (Table 2). Table 3 shows the breakdown and costing of further testing in the MRPP > 25 group.

\section{Discussion}

The results of the present study suggests that in patients with no known CAD, regardless of functional capacity (treadmill exercise duration), any EST that is terminated at volitional fatigue, with no ECG evidence or symptoms of myocardial ischemia, and yields an MRPP $>25000$ provides reassurance that there was no clinically significant 
Table 2. Results of further testing for maximum rate pressure product (RPP) groups (as defined in text).

\begin{tabular}{|c|c|c|c|c|c|c|}
\hline \multirow[b]{2}{*}{ Further testing } & \multicolumn{3}{|c|}{ Maximum RPP > 25000} & \multicolumn{3}{|c|}{ Maximum RPP $<25000$} \\
\hline & Total & Outcome & Angiogram & Total & Outcome & Angiogram \\
\hline Exercise stress test & 0 & & & 1 & (0) & \\
\hline Resting echocardiogram & 1 & (0) & & 2 & (0) & \\
\hline \multirow[t]{2}{*}{ Dobutamine stress echocardiogram } & 10 & (0) & & 23 & $5(+)$ & $4(+)$ \\
\hline & & 1 re-presented & $1(0)$ & & 3 re-presented & $3(0)$ \\
\hline Exercise stress echocardiogram & 7 & (0) & & 2 & (0) & \\
\hline \multirow[t]{2}{*}{ Myocardial perfusion scan } & 36 & $8(+)$ & $8(0)$ & 71 & $12(+)$ & $2(+)$ \\
\hline & & & & & 10 re-presented & $2(+)$ \\
\hline CTCA & 10 & (0) & & 1 & (0) & \\
\hline Coronary angiogram & 5 & (0) & & 11 & $3(+)$ & \\
\hline DNA & 30 & 3 re-presented & $3(0)$ & 26 & 2 re-presented & $2(0)$ \\
\hline
\end{tabular}

All values show number of cases. $(+)$ indicates positive, (0) indicates negative; CTCA — computed tomography coronary angiography; DNA did not attend follow-up appointment

Table 3. The breakdown of costing from additional testing procedures in the maximum rate pressure product $>25$ group*. Angiogram figures and computed tomography coronary angiography (CTCA) are based on the average cost of tests performed.

\begin{tabular}{lccc}
\hline Test & Total No. & Cost (\$AUS) & Total cost (\$AUS) \\
\hline Resting echocardiogram & 1 & 230.65 & 230.65 \\
Dobutamine stress echocardiogram & 10 & 413.80 & 4130.80 \\
Exercise stress echocardiogram & 7 & 413.80 & 2896.60 \\
Myocardial perfusion scan & 36 & 834.90 & 30056.40 \\
CTCA & 10 & 700.00 & 7000.00 \\
Angiogram & 17 & 855.50 & 14543.50 \\
All tests & 81 & & 58857.95 \\
\hline
\end{tabular}

*MBS Online Medicare Benefits Schedule, Australian Government, Department of Health, viewed 27 July 2016, http://www.health.gov.au/ /internet/mbsonline/publishing.nsf/Content/a-z.

CAD for up to 2 years follow-up, potentially alleviating the need for further downstream testing.

In the current study MRPP outperformed an APMHR of $\geq 85 \%$ for sensitivity ( $97 \%$ vs. $60 \%$ ) with a nominal difference in specificity $(45 \%$ vs. $53 \%$ ) for the occurrence of CV events during the mean follow up (5 years). The sensitivity of $97 \%$ displayed for MRPP in the current study provides great incremental value to an EST performed at reduced functional capacity, as very few of these patients had $\mathrm{CV}$ events during mean follow up (5 years). The specificity although modest at $45 \%$, is a reflection of the negative downstream testing that would otherwise not have been performed in the MRPP > 25 group. This could therefore be considered extraneous, as clinical advantage has already been established due to the high sensitivity and warranty periods on EST are not clearly established [14, 15].
While the difference between the ROC curves failed to reach significance $(z=1.8, p=0.072)$, the AUC for MRPP (0.76) over MHR (0.59) clearly demonstrates a superior predictive model. Achieving $85 \%$ of APMHR has been demonstrated to be a poor diagnostic and functional endpoint [16]. Traditionally, the inability of HR to reach this figure has been seen as a marker of chronotropic incompetence and a predictor of adverse CV outcome [17-19]. Many of these studies however did not report the corresponding SBP with HR and therefore the MRPP was achieved [17, 18]. A study by Elhendy et al. [19] although not discussed in their findings, clearly demonstrated a significantly reduced MRPP in the group that failed to reach $85 \%$ of APMHR. Therefore it may be seen that the SBP response to exercise should be just as important as the corresponding HR response. Bouzas-Mosquera et al. [20] demonstrated 
that a substantial increase in SBP alone during exercise testing was associated with a significantly lower risk of mortality and CV events. Individuals achieving greater increases in RPP during exercise have also been shown to have less CV events over time in both those with, and without significant CAD [4, 5, 21]. The current study confirms this finding, where a significant difference in CV-related events was observed between the two groups from 2 years follow up ( $<<0.05$; Fig. 3$)$. A similar significant difference between the groups was observed for RPPR $(p<0.01)$, and although all-cause mortality did not reach statistical significance in the current study, previous studies have demonstrated a similar prognostic advantage when a higher RPPR is achieved [4, 5]. Sadrzadeh Rafie et al. [4] showed that RPPR possessed a greater prognostic power than functional capacity (METS) when comparing individuals with similar functional capacities (> 5 METS). Functional capacity (METS) has been shown to be an important prognostic measure for future CV events and mortality [21-23], and likewise the current findings demonstrated a significant difference between the groups for this measure. Allowing that RPP reflects myocardial oxygen consumption [24, 25], it would therefore seem reasonable that the ability to significantly increase RPP in the absence of any substantial pathology, be reflective of a normal functioning left ventricle.

Age was the only variable that was statistically significant $(p=0.02)$ for the prediction of $\mathrm{CV}$ events. This in itself would normally predict a better prognosis and may have also contributed to the older groups (MRPP $<25$ ) poorer treadmill time and inability to produce a MRPP $>25000$. Nevertheless the average age of both groups was over 50 years (Table 1 ) MRPP $>25=50.1 \pm 10.6$ and MRPP $<25=54.9 \pm 11.6$ and Lloyd-Jones et al. [26] demonstrated that having $\geq 2$ major CV risk factors at the age of 50 years substantially increased lifetime CV risk and mortality. In the current study, there was no difference between groups in regard to the number of CV risk factors $(\mathrm{p}=0.1)$ with both groups possessing greater than 2 (Table 1 ). It would therefore be reasonable to accept that patients in the current study although exhibiting a difference in age, in general still carried a similar increased risk for future $\mathrm{CV}$ events.

There were no patients in the current study achieving a MRPP > 25000 during their EST with a positive downstream test during the initial 2 year follow-up. Thus, there is potential for significant cost savings by avoiding further testing without compromising safety. The total number of additional tests performed in patients with a MRPP $>25000$ was 81 . Of concern are the additional 8 angiograms that were required when the follow-up cardiac stress testing (myocardial perfusion imaging) yielded false positive results. The 81 tests would not have been required under the proposed model, and would have provided a total cost savings for the documented facility of approximately AUS $\$ 59,000$ with identical patient outcomes in the mean follow-up period (Table 3) [27].

While inducible myocardial ischemia typically occurs at a similar RPP for an individual $[2,28]$, a set ischemic threshold is not established between individuals as this can occur at varying RPP, depending on the extent of the ischemia, vessels involved and compensatory mechanisms present $[29,30]$. Furthermore, patients that achieve certain parameters that are interpreted as eliciting sufficient cardiac stress, such as $>85 \%$ target heart rate or $>10$ METS, are not necessarily immune from significant CAD causing myocardial ischemia [13, 31]. It is for this reason that it should be recommended that an MRPP of 25000 not be used as an arbitrary termination point but rather as reassurance once maximal fatigue has been reached and the test is otherwise negative for myocardial ischemia.

\section{Limitations of the study}

The present study is a single center cohort study and, therefore, may be subject to selection bias. While the outcome data demonstrates statistical significance for CV events and mortality, the AUC for MRPP (0.76) indicates a moderate predictive model and further studies with greater numbers would be beneficial in order to confirm these observations. Although there was no clinical evidence of HF prior to EST, echocardiography to assess for signs of left ventricular dysfunction prior to testing would have been an advantage. Finally, the use of MRPP as an index of adequate cardiac stress should not replace the clinical decision to use downstream testing in those individuals deemed to have sufficient risk and high suspicion of CAD.

\section{Conclusions}

The data herein, suggests that in patients with an intermediate pre-test risk and no previous CAD, any EST that is terminated at maximal fatigue with patients attaining a MRPP $>25000$ and no electrocardiogram evidence or symptoms of myocardial ischemia, do not require further 
downstream testing. Furthermore, this group of patients, while not immune to future CV events, have significantly better outcomes than those not attaining a MRPP $>25000$.

\section{Acknowledgements}

Mark Whitman is supported by an Australian Government Research Training Program Scholarship.

\section{Conflict of interest: None declared}

\section{References}

1. Hui SC, Jackson AS, Wier LT. Development of normative values for resting and exercise rate pressure product. Med Sci Sports Exerc. 2000; 32(8): 1520-1527, indexed in Pubmed: 10949021.

2. Fletcher GF, Balady GJ, Amsterdam EA, et al. Exercise standards for testing and training: a statement for healthcare professionals from the American Heart Association. Circulation. 2001; 104(14): 1694-1740, indexed in Pubmed: 11581152.

3. Pinkstaff S, Peberdy MA, Kontos MC, et al. Quantifying exertion level during exercise stress testing using percentage of age-predicted maximal heart rate, rate pressure product, and perceived exertion. Mayo Clin Proc. 2010; 85(12): 1095-1100, doi: 10.4065/ mcp.2010.0357, indexed in Pubmed:21123636.

4. Sadrzadeh Rafie AH, Sungar GW, Dewey FE, et al. Prognostic value of double product reserve. Eur J Cardiovasc Prev Rehabil. 2008; 15(5): 541-547, doi: 10.1097/HJR.0b013e328305deef, indexed in Pubmed: 18665099.

5. Villella M, Villella A, Barlera S, et al. Prognostic significance of double product and inadequate double product response to maximal symptom-limited exercise stress testing after myocardial infarction in 6296 patients treated with thrombolytic agents. Am Heart J. 1999; 137(3): 443-452, doi:10.1016/s0002-8703(99)70490-4.

6. Sadrzadeh Rafie AH, Dewey FE, Sungar GW, et al. Age and double product (systolic blood pressure $\mathrm{x}$ heart rate) reserve-adjusted modification of the Duke Treadmill Score nomogram in men. Am J Cardiol. 2008; 102(10): 1407-1412, doi: 10.1016/j.amjcard.2008.07.020, indexed in Pubmed:18993164.

7. Fornitano LD, Godoy MF. [Increased rate-pressure product as predictor for the absence of significant obstructive coronary artery disease in patients with positive exercise test]. Arq Bras Cardiol. 2006; 86(2): 138-144, doi: /S0066-782X2006000200010, indexed in Pubmed: 16501806.

8. Snader CE, Marwick TH, Pashkow FJ, et al. Importance of estimated functional capacity as a predictor of all-cause mortality among patients referred for exercise thallium single-photon emission computed tomography: report of 3,400 patients from a single center. J Am Coll Cardiol. 1997; 30(3): 641-648, indexed in Pubmed: 9283520.

9. Gulati M, Black HR, Shaw LJ, et al. The prognostic value of a nomogram for exercise capacity in women. N Engl J Med. 2005; 353(5): 468-475, doi:10.1056/NEJMoa044154, indexed in Pubmed: 16079370.

10. Bruce RA, Blackmon JR, Jones JW, et al. Exercising testing in adult normal subjects and cardiac patients. Pediatrics. 1963; 32(suppl): 742-756.

11. Morris CK, Myers J, Froelicher VF, et al. Nomogram based on metabolic equivalents and age for assessing aerobic exercise capacity in men. J Am Coll Cardiol. 1993; 22(1): 175-182, indexed in Pubmed: 8509539.

12. Bruce RA, Kusumi F, Hosmer D. Maximal oxygen intake and nomographic assessment of functional aerobic impairment in cardiovascular disease. Am Heart J. 1973; 85(4): 546-562, indexed in Pubmed: 4632004.

13. National Vascular Disease Prevention Alliance. Guidelines for the management of absolute cardiovascular disease risk. 2012.
14. Engineer RS, Lauer MS, Emerman CL. Chest pain after recent stress test: Is there a warranty? Ann Emerg Med. 2004; 44(4): S47, doi:10.1016/j.annemergmed.2004.07.153.

15. Romero-Farina G, Candell-Riera J, Aguadé-Bruix S, et al. Warranty periods for normal myocardial perfusion stress SPECT. J Nucl Cardiol. 2015; 22(1): 44-54, doi: 10.1007/s12350-014-9957-6, indexed in Pubmed: 25116906.

16. Jain M, Nkonde C, Lin BA, et al. 85\% of maximal age-predicted heart rate is not a valid endpoint for exercise treadmill testing. J Nucl Cardiol. 2011; 18(6): 1026-1035, doi: 10.1007/s12350-011-9454-0, indexed in Pubmed: 21922347.

17. Ellestad MH, Wan MK. Predictive implications of stress testing. Follow-up of 2700 subjects after maximum treadmill stress testing. Circulation. 1975; 51(2): 363-369, indexed in Pubmed: 1112017.

18. Lauer MS, Okin PM, Larson MG, et al. Impaired heart rate response to graded exercise. Prognostic implications of chronotropic incompetence in the Framingham Heart Study. Circulation. 1996; 93(8): 1520-1526, indexed in Pubmed: 8608620.

19. Elhendy A, Mahoney DW, Khandheria BK, et al. Prognostic significance of impairment of heart rate response to exercise: impact of left ventricular function and myocardial ischemia. J Am Coll Cardiol. 2003; 42(5): 823-830, indexed in Pubmed: 12957427.

20. Bouzas-Mosquera MC, Bouzas-Mosquera A, Peteiro J. Excessive blood pressure increase with exercise and risk of all-cause mortality and cardiac events. Eur J Clin Invest. 2016; 46(10): 833-839, doi: 10.1111/eci.12665, indexed in Pubmed: 27505135.

21. Farzaneh-Far R, Na B, Whooley MA, et al. Left-ventricular power-tomass ratio at peak exercise predicts mortality, heart failure, and cardiovascular events in patients with stable coronary artery disease: data from the Heart and Soul Study. Cardiology. 2009; 114(3): 226-234, doi: 10.1159/000231991, indexed in Pubmed: 19672059.

22. Myers J, Prakash M, Froelicher V, et al. Exercise capacity and mortality among men referred for exercise testing. $\mathrm{N}$ Engl J Med. 2002; 346(11): 793-801, doi: 10.1056/NEJMoa011858, indexed in Pubmed: 11893790

23. Bourque JM, Holland BH, Watson DD, et al. Achieving an exercise workload of $>$ or $=10$ metabolic equivalents predicts a very low risk of inducible ischemia: does myocardial perfusion imaging have a role? J Am Coll Cardiol. 2009; 54(6): 538-545, doi: 10.1016/j. jacc.2009.04.042, indexed in Pubmed: 19643316.

24. Gobel FL, Norstrom LA, Nelson RR, et al. The rate-pressure product as an index of myocardial oxygen consumption during exercise in patients with angina pectoris. Circulation. 1978; 57(3): 549-556, indexed in Pubmed: 624164.

25. Nelson RR, Gobel FL, Jorgensen CR, et al. Hemodynamic predictors of myocardial oxygen consumption during static and dynamic exercise. Circulation. 1974; 50(6): 1179-1189, indexed in Pubmed: 4430113.

26. Lloyd-Jones DM, Leip EP, Larson MG, et al. Prediction of lifetime risk for cardiovascular disease by risk factor burden at 50 years of age. Circulation. 2006; 113(6): 791-798, doi: 10.1161/CIRCULATIONAHA.105.548206, indexed in Pubmed: 16461820.

27. MBS Online Medicare Benefits Schedule [Internet]. Australian Government, Department of Health; 2016.http:/www.health.gov.au/ internet/mbsonline/publishing.nsf/Content/a-z (cited 2016 July 27).

28. Gibbons RJ, Balady GJ, Beasley JW, et al. ACC/AHA Guidelines for Exercise Testing. A report of the American College of Cardiology/ /American Heart Association Task Force on Practice Guidelines (Committee on Exercise Testing). J Am Coll Cardiol. 1997; 30(1): 260-315, indexed in Pubmed:9207652.

29. Lekven J, Mjos OD, Kjekshus JK. Compensatory mechanisms during graded myocardial ischemia. Am J Cardiol. 1973; 31(4): 467-473, indexed in Pubmed: 4692582.

30. Vigorito C, De Caprio L, Poto S, et al. Protective role of collaterals in patients with coronary artery occlusion. Int J Cardiol. 1983; 3(4): 401-415, indexed in Pubmed: 6885187.

31. Peteiro J, Bouzas-Mosquera A, Broullón F, et al. Value of an exercise workload $\geq 10$ metabolic equivalents for predicting inducible myocardial ischemia. Circ Cardiovasc Imaging. 2013; 6(6): 899-907, doi: 10.1161/CIRCIMAGING.113.000413, indexed in Pubmed: 24036386 